EMBRYAIDDLE

Aeronautical University

SCHOLARLY COMMONS
International Journal of Aviation, Aeronautics, and Aerospace

\title{
An Evaluation of the Relationships between Collegiate Aviation Safety Management System Initiative, Self-Efficacy, Transformational Safety Leadership and Safety Behavior mediated by Safety Motivation
}

Daniel Kwasi Adjekum

University of North Dakota, kadjekum@yahoo.com

Follow this and additional works at: https://commons.erau.edu/ijaaa

Part of the Aerospace Engineering Commons, Aviation and Space Education Commons, Aviation Safety and Security Commons, Community College Leadership Commons, Curriculum and Instruction Commons, Curriculum and Social Inquiry Commons, Educational Assessment, Evaluation, and Research Commons, Educational Psychology Commons, International and Area Studies Commons, Leadership Studies Commons, Management and Operations Commons, Science and Mathematics Education Commons, Social and Philosophical Foundations of Education Commons, Student Counseling and Personnel Services Commons, and the Vocational Education Commons

\section{Scholarly Commons Citation}

Adjekum, D. K. (2017). An Evaluation of the Relationships between Collegiate Aviation Safety Management System Initiative, Self-Efficacy, Transformational Safety Leadership and Safety Behavior mediated by Safety Motivation. International Journal of Aviation, Aeronautics, and Aerospace, 4(2). https://doi.org/10.15394/ijaa.2017.1169

This Article is brought to you for free and open access by the Journals at Scholarly Commons. It has been accepted for inclusion in International Journal of Aviation, Aeronautics, and Aerospace by an authorized administrator of Scholarly Commons. For more information, please contact commons@erau.edu. 


\section{An Evaluation of the Relationships between Collegiate Aviation Safety Management System Initiative, Self-Efficacy, Transformational Safety Leadership and Safety Behavior mediated by Safety Motivation \\ Cover Page Footnote \\ Special thanks to all the respondents who took part in the survey.}


An accident in any collegiate aviation program could have negative impact on flight operations and lead to loss of lives, equipment, reputation, and customer confidence in the overall training program of any flight training service provider (ASN, 2008; ICAO, 2009; NTSB, 2010). Some collegiate aviation programs in the US have implemented proactive safety initiatives to mitigate risks associated with their training operations and improve the safety culture (Adjekum, 2014a).

Safety initiatives such as Safety Management Systems (SMS) has positively affected the safety culture, and subsequently enhanced the accident prevention strategies in these collegiate aviation programs by engendering a proactive operational safety regime that is based on a data-centered risk management process (Adjekum, 2015). The data-centered risk management process enables collegiate aviation personnel to identify flight safety hazards and report these hazards through well-structured safety reporting systems.

SMS implementation at the collegiate level enables program managers to identify significant safety trends through data accrued from safety reporting systems and flight data-monitoring systems. Based on these trends, risk assessment strategies and risk controls are applied by these managers to reduce safety occurrences to a level that is as low as reasonably possible (ICAO, 2013). Additionally, continuous monitoring of the effectiveness of such controls and improvement mechanisms complete a cyclical process (Adjekum, 2014a; Adjekum, 2015: ICAO, 2013).

The International Civil Aviation Organization (ICAO) defines SMS as an organized approach to managing safety, including the necessary organizational structures, accountabilities, policies and procedures (ICAO, 2013). The FAA defines SMS as a formal, top-down, organization-wide approach to managing safety risk and assuring the effectiveness of safety risk controls (FAA, 2015b). An SMS is a management device that uses proactive tools, in addition to reactive ones and relies on safety performance with a focus on processes. An SMS is an effective tool in hazards identification and mitigation of risks before operational safety is threatened. An SMS consists of four main components: Safety Policy and Objectives, Safety Risk Management, Safety Assurance, and Safety Promotion. These four main components comprise twelve sub-components (ICAO, 2013).

An organizational safety effort cannot succeed just by the mechanical implementation of the referred SMS components and procedures. An effective SMS is built taking due account of the interaction between these components and the human element of aviation operations (Stolzer, Halford, \& Goglia, 2011). A successful implementation any SMS initiative is highly dependent on 
organizational aspects such as individual and group attitudes, values, competencies and patterns of behavior, which are frequently referred to as elements of the organizational safety culture (Cooper, 2000; ICAO, 2009). A positive safety culture is characterized by a shared awareness of organization's personnel of the importance of safety in their operational tasks.

There could be challenges for management of collegiate flight programs to ensure that the SMS implementation within the organization positively influences the behavior of personnel such as flight instructors and students (Adjekum, 2014a; Cooper, 2000). It is important for leadership of collegiate aviation programs who provide the strategic direction and control of resources to evaluate the effectiveness of SMS implementation, since a lot of time and resources would have been invested and returns on investments such as continuous improvements in safety performance are critically desired (Adjekum, 2014a).

Conversely, the impact of variables such as beliefs, opinions and perceptions of collegiate aviation personnel on transformational leadership attributes among top- level management, personal self-efficacy and safety motivation and how it affects safety behavior needs constant assessment. This assessment is essential because of the concomitant effects on safety performance outcomes, such as incidents and accidents (Adjekum, 2014a; Chen, 2014; Freiwald, 2013).

Effective SMS implementation has been shown to have a positive effect on the safety perceptions of front line personnel in high reliability organizations such as aviation, and improved safety behaviors (Adjekum et al., 2015; von Thaden, 2008). Chen (2014) in a study among pilots in Taiwanese airlines suggested significant effects within the interactions between perceptions on SMS practice, safety leadership, self-efficacy, and safety behavior with safety motivation as a mediating variable.

Transformational safety leadership is another variable that has been suggested to influence safety behavior and invariably safety related outcomes like violations, incidents and accidents. In studies by Zohar (2002), for example, the role of leadership has been emphasized as a factor in improving safety. Additionally, studies by Barling, Loughlin, and Kelloway (2002) have focused on the effects of transformational safety leadership on safety promotion. A challenge and gap in research is establishing a coherent relationship between these variables using a quantitative approach in collegiate aviation programs in the US. This current approach can provide a clearer picture of the inter-relationships between 
these variables and how it affects continuous monitoring and improvement of safety in collegiate flight operations.

\section{Purpose of the Study}

In this study, a quantitative research approach was used to examine the relationship between the perceptions of collegiate aviation flight personnel (Flight students including those with certified flight instructor ratings employed in the program) on Safety Management System (SMS) initiatives, transformational safety leadership (TSL), self-efficacy (SE), and self-reported safety behaviors while mediating with safety motivation. Safety behavior was measured by safety compliance (SC) and safety participation (SP).

\section{Literature Review}

Generally, there has been a paucity of literature and studies on SMS in collegiate aviation, due to few programs implementing the voluntary FAA SMS initiative (SMSVP), since it is not a mandatory regulatory requirement in the US (FAA, 2015a; FAA, 2015b; UND, 2012). Some of the indirect studies on SMS in collegiate aviation have been targeted at safety climate/culture assessments (Adjekum, 2014a; Adjekum et al., 2015; Dillman, Voges, \& Robertson, 2010; Freiwald, Lenz-Anderson, \& Baker, 2013).

Nominally, safety management in aviation operations has focused on prescription-based regulation compliance, and accordingly the main tool used for safety improvement is guaranteeing compliance with such prescriptive regulations (FAA, 2013; ICAO, 2009). The challenge in safety management is the reality that prescriptive regulation may not address all the specific hazards that are likely to exist in different aviation organizations and contexts. Prescriptive regulations may also not have effective control measures against all the specific hazards and its attendant risks in aviation organizations (Dekker, 2011; Reason, 1997; Stolzer, Halford \& Goglia, 2008).

Therefore, although regulatory compliance may be achieved in an aviation operator's activities, organizational and contextual factors may cause people to make errors and thereby imperil organizational safety (Reason, 1997). There has also been a contemporary advocacy by ICAO, for a shift from prescription-based safety management to a performance-based management of safety, where the goal is to observe higher than anticipated leading safety performance indicators relative to key safety targets pre-established, such as higher frequency of personnel safety training and self-reporting of safety issues by front-line personnel (FAA, 2012; 
ICAO, 2013; Remawi, Bates, \& Dix, 2011). The extent to which these practices are implemented in an organization will be manifested through various actions and programs of the management and will be clearly visible to an insider like an employee (Adjekum, 2014b; FAA, 2012; Stolzer, Halford, \& Goglia, 2008).

A performance-based approach to safety management combines prescribed standards with performance standards. What is essentially expected from aviation organizations is a continuous improvement in safety performance, as well as compliance with regulations (ICAO, 2013). Most high-reliability organizations (HROs) use proactive tools such as hazard identification and risk analysis, safety measurement, safety performance monitoring and prediction to fulfill these expectations. Aviation organizations, most of which are HROs should demonstrate that they can manage their own customized hazards and risks in a contextual dynamic environment, while the national aviation regulatory authority can focus on overseeing the effectiveness of the organization's SMS (ICAO, 2013; FAA, 2012).

The validation process for collegiate aviation programs who want to be part of the SMSVP can be long and requires a lot of resources. The following categories denote the progress expected from the SMSVP participants by the FAA:

1. The first level of SMSVP Active Applicant is when the certificate holder (collegiate program) and certificate maintenance team (CMT) have committed to sufficiently support the SMS implementation and validation processes.

2. The second phase of SMSVP Active Participant is the actual level, where the certificate holder officially begins and maintains its implementation efforts.

3. The third level of SMSVP Active Conformance is attained when the CMT and SMS program Office (SMSPO) acknowledge full implementation of the certificate holder's SMS. By this stage, the certificate holder is expected to use and continually improve its safety management processes.

Within the collegiate aviation operational environment in the United States, the number of studies related to the SMS is relatively limited (Adjekum, 2014b) and most of the reviews would be on the broader perspective of SMS in high reliability organizations such as aviation. Gill and Shergill (2004) studied employee perceptions of SMS and safety culture in New Zealand's aviation industry and tried to develop a scale to assess the management of safety. Their study also focuses on safety culture and rather than define what the components and elements of a successful SMS were, the authors rather considered the current 
approach to safety management within the organizations being studied in a general manner.

Fernández-Muñiz, Montes-Peón, and Vázquez-Ordás (2007) analyzed various studies that emphasized the importance of Safety Management Systems (SMS) and how to implement them. The authors however, discovered that there were very few works providing a specific tool to measure the degree of implementation of the policies and practices making up this management system in organizations. The authors conceptualized SMS and followed up with a risk management process that described the essential elements making up the SMS. This management process provided the basis for identifying, in turn, a set of variables that would be used to develop an instrument to measure the degree of implementation of such a process.

In a study on the effect of employee perceptions on six SMS practices and self-reported safety knowledge, safety motivation, safety compliance and safety participation, Vinodkumara and Bhasib (2010) conducted a survey using questionnaire among 1566 employees belonging to eight major accident hazard process industrial units in Kerala, a state in southern part of India. The researchers found out that the reliability and unidimesionality of all the scales were acceptable.

In that study, path analysis using AMOS-4 software showed that some of the SMS practices had direct and indirect relations with the safety performance components, namely, safety compliance and safety participation. Safety knowledge and safety motivation were found to be the key mediators in explaining these relationships. Safety training was identified as the most important safety management practice that predicted safety knowledge, safety motivation, safety compliance and safety participation.

Liou and Chuang (2010) mapped out structural relationships among diverse components of SMS and identified key factors in their model. A similar study was conducted by Hsu, Li, and Chen (2010) to develop an analytical framework for defining the key components and dimensions of an airline SMS and their interaction. Chen and Chen (2012) developed a customized SMS evaluation scale for the airline industry based on the perceptions of aviation experts and airline managers.

Chen (2014) examined the effects of pilots' perceptions of Safety Management System (SMS) practices, fleet managers' morality leadership and pilots' self-efficacy on flight crews' safety behaviors through the mediation of safety motivation. Using a sample of 239 Taiwanese commercial pilot participants, and Structural Equation Modeling (SEM) technique, the results indicated that both 
perceptions of SMS practices and self-efficacy have direct, positive effects on pilots' safety behaviors (safety participation and safety compliance), while the effect of fleet managers' morality leadership on such behavior was fully mediated by pilots' safety motivation.

Several studies (Fernández-Muñiz, Montes-Peón, \& Vázquez-Ordás, 2014; Kapp, 2012; Kelloway, Mullen, \& Francis, 2006; Pilbeam, Doherty, Davidson, \& Denyer, 2016; Zohar, 2002) have found relationships between safety-specific transformational leadership (i.e. Transformational leadership specifically focused on enhancing individual and organizational safety) and safety-related outcomes, including perceived safety climate, safety events, safety consciousness, and safety citizenship behavior (Conchie \& Donald, 2009; Kelloway, Mullen, \& Francis, 2006).

Christian, Bradley, Wallace, and Burke (2009) further suggest that generally, front line personnel who have high-quality relationships with their leaders are more likely to have more positive safety behaviors because the leader and the personnel would have connected to solve problems together. They also suggest that personnel who have positive interactions with their leaders are more likely to respond to their leaders positively than their colleagues who do not have such positive interactions. Zohar (2002) found out that personnel in a factory who were exposed to transformational safety leadership had higher levels of safety compliance (as measured by earplug use) when compared with a control group.

However, several issues remain with transformational safety-specific leadership. First, the salience of safety as an important outcome in the presence of safety-focused leaders is understandable; there has been long standing research (Cohen, 1977; Zohar, 1980) showing that organizations in which leaders take an active role in promoting safety enjoy better organizational safety records. Transformational safety-specific leadership, when used as the sole predictor of safety outcomes may confound safety performance and transformational leadership. The possibility remains that a safety climate (Wallace \& Chen, 2006; Zohar, 2002) rather than transformational leadership behaviors per se explains variance in employee safety performance.

Theoretically there are competing schools of thought on the effects of safety motivation, self-efficacy, operational environment and leadership on safety behaviors and outcomes. Abraham Maslow introduced the Hierarchy of Needs Theory (Maslow, 1970) to explain human motivations and needs. In this theory, Maslow proposed that all human beings are motivated by unsatisfied needs and that certain lower factors need to be satisfied before higher needs can be satisfied. 
Maslow's Hierarchy Theory underpins the essence of identifying those underlying potential motivational factors that can enhance proactive safety behavior in collegiate aviation programs (McLeod, 2014). Collegiate flight student's cognitive needs, which affect their decision-making process and largely safety behavior, can be enhanced if their basic physiological needs are met.

McGregor's Theory $X$ postulates that the main source of most employee motivation is monetary, with security as a strong second and leaders can manage safety behavior by coercion, threats, or micromanagement (Sorenson, 2015; Stewarts, 2010). On the contrary, McGregor's Theory $Y$ postulates that that employees are motivated primarily at the esteem and self-actualization levels and that leadership in Theory $Y$ makes the following general assumptions that personnel will be self-directed and creative to meet their work and organizational safety objectives if they are committed to them. The theory further advances the notion that personnel will be committed to their safety and productivity objectives if rewards that address higher needs such as self-fulfillment are in place. This aspect of the Theory $Y$ has profound implications for personnel to have "buy-in" and participate in safety programs initiated in collegiate aviation program.

Frederick Herzberg's Motivational Theory (Two-Factor Theory) on the other hand, states that motivation can be split into two major categories: hygiene factors and motivation factors. Herzberg's Hygiene factors include the following: supervision, interpersonal relationships, physical working conditions and salary. Job dissatisfaction, under normal circumstances, is not normally attributed to motivation factors. However, when they are present, they serve as motivational factors. Motivation factors include achievement, advancement, recognition and responsibility (Greenberg, 2013; Hines, 1973; Neil, 2007).

The drawback of this theory and implication on safety behavior is that whenever there is shortage of motivation factors present in the work environment, personnel may focus on other factors, such as the hygiene factors and when there are unfavorable working conditions and production pressures under limited resources resulting in job dissatisfaction, that could be a recipe for unsafe behaviors and possible accidents (Schultz \& Schultz, 2010).

According to the Operant Learning Theory, behavior is a function of the person's environment and can be modified by rearranging the consequences of the behavior (Skinner, 1953). Per Skinner, behavior with positively reinforcing consequences (e.g., increased earnings or reductions in amount of effort required to do a task) tends to increase in frequency, whereas behavior with punishing consequences (e.g., disciplinary actions) tends to diminish in frequency. The implications of this theory for operational safety, especially in a flight training 
environment is that personnel may tend to act safely, and follow training guidelines and safety instructions since the outcomes are positive as compared to unsafe acts, which may have adverse consequences. This assertion may not always hold true, since personnel may not know the outcome of certain actions, especially in novel situations and would only get to know of the outcome in hindsight. Some personnel may also engage in some operational activities in an unsafe manner, but due to the absence of other vital pre-cursors of accident causation, such as unsafe conditions or just plain luck, nothing adverse happen, creating an illusion of invulnerability (Reason, 2008).

Another theoretical foundation to human behavior has been proposed by Ajzen $(1991 ; 2005)$ in the Theory of Planned Behavior (TPB). The theory explains the psychological aspects of employee behavior and the principal assumption of the TPB has to do with the intentions behind any human action. Per Fogarty and Shaw (2009), an individual's own attitude toward behavior, subjective norms, and perceived behavioral control can be used to predict intentions regarding any safety issue. Intention can in this way be used to predict actual safety behavior.

Research suggests that people with high levels of self-efficacy have greater beliefs in their own capabilities to achieve certain goals and that pilots with higher perceived self-efficacy are likely to better resist pressure and devote more efforts to improving their work-related and management performance (Schwarzer \& Jerusalem, 1995). Individual self-efficacy has been applied as the observed predictor in the number of studies that investigate pilots' work-related behaviors (Parasuraman, Molloy, \& Singh, 1993; Prinzel, 2002). Prior research demonstrates that self-efficacy has effects on the level of motivation, learning and performance (Schunk \& Pajares, 2001). Graham and Weiner (1995), for example, stated that self-efficacy is a consistent predictor of behavior and behavioral change.

Neal and Griffin (2002) also hypothesized that safety behavior could be defined by the underlying construct measures of safety compliance and safety participation. While Neal and Griffin (2002) suggested that safety climate is one of the potential predictors of safety behavior, they further identified other potential predictors of safety behavior as supportive leadership and conscientiousness.

In a previous study, Griffin and Neal (2000) suggested that conscientiousness predicted safety motivation, safety compliance, and safety participation. Other studies have suggested that a key component of conscientiousness is self-efficacy (Chen, 2014; Scwazzer \& Jerusalem, 1995). In other studies, Neal and Griffin (2006) found that perceptions of knowledge about safety and motivation to perform work functions safely significantly influenced 
self-report of task and contextual safety performance, namely safety compliance and safety participation.

\section{Research Questions}

1. What are the factors that measure the latent construct of SMS initiative?

2. What is the effectiveness of a proposed measurement model as compared to that of a final measurement model that assesses the relationships between SMS initiative, transformational safety leadership, self-efficacy, and the outcome variable safety behavior measured by safety compliance and safety participation, when mediated by safety motivation?

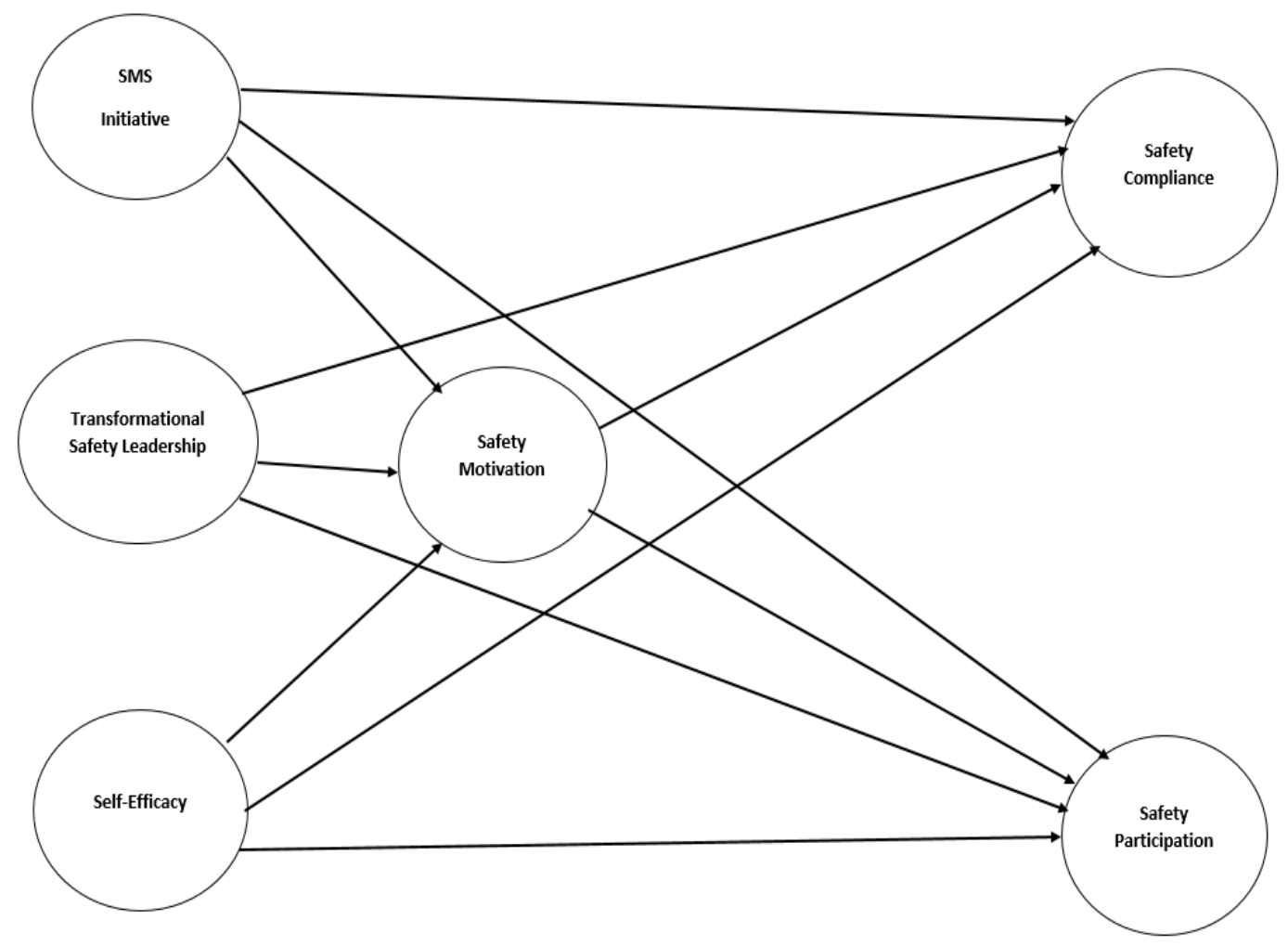

Figure 1. SEM-PA of hypothesized measurement model of relationship between SMS, TSL, SE, SM, SP and SC.

\section{Method}

The study focused on the responses to items in a survey instrument from a random sample of respondents enrolled in flight-related courses in a collegiate 
aviation program (49 CFR Part 141) of a public-owned university in the United States $(N=800)$. The aviation program in the university has been recognized by the FAA as attaining the active conformance level in the implementation of the voluntary SMS program.

\section{Survey Instrument}

A quantitative survey instrument with forty-six items representing the seven constructs and six demographic variables was used to examine the relationships between the perceptions of these collegiate aviation respondents (i.e., flight students including those with certified flight instructor ratings and employed by the program) on the constructs Safety Management System (SMS) initiatives, Transformational Safety Leadership (TSL), Self-Efficacy (SE), and Self-Reported Safety Behaviors (SB), and Safety Motivation (SM). Safety behavior was measured by Safety Compliance (SC) and Safety Participation (SP).

All the constructs were measured using a five-point Likert-type scale ( $1=$ strongly disagree; $5=$ strongly agree $)$ or $(1=$ very rarely; $5=$ very frequent $)$. To assess the reliability of scales, which refers to a variable or a set of indicators of a latent construct being internally consistent in their measurements (Fields, 2009), Cronbach's coefficient was applied with a minimum alpha value $(\alpha=0.70)$ being considered adequate for all the results in line with social science research (Nunally, 1978; Stevens, 2002; Fields, 2009). The various constructs were measured using these validated instruments:

a) SMS initiative- Chen and Chen (2012), Chen (2014), Transport Canada (2005). An example of an item in the scale is "The safety policy is signed and approved by the Dean, who demonstrates a strong commitment to safety through active and visible participation in the safety management system". The reported reliability was 0.93 .

b) Self-efficacy - Schwazzer and Jerusalem (1995). Four items in the scale were used and sample items are "I can solve most problems if I invest the necessary effort,' and 'It is easy for me to stick to my aims and accomplish my goals.' The reported coefficient alpha was 0.86 .

c) Safety motivation- Neal and Griffin (2006). Examples of items in this scale are: "I feel it is important to maintain safety at all times," and "I believe that it is important to reduce the risk of accidents and incidents in flight operations.' The reported coefficient alpha for this scale was 0.90 .

d) Safety behavior (Safety compliance and Safety participation) - Neal, Griffin, and Hart (2000), Neal and Griffin (2006). Safety compliance evaluates the core tasks that pilots must accomplish to maintain flight 
safety. An example of an item in the safety compliance scale is "I pay full attention to the pre-flight briefing to collect sufficient data for every flight.", Safety participation assesses the extent to which pilots help develop an environment that supports safety. An example of an item was "I attend aviation safety programs organized in the school.' The reported coefficient alpha values for safety compliance and safety participation are 0.91 and 0.84 , respectively.

e) Transformational safety leadership - Survey of Transformational Leadership (STL) developed by Edwards, Knight, Broome and Flynn (2010). The alpha coefficient to measure the internal consistency of the scale had scores ranging from 0.84 (Supports others) to 0.97 (Inspirational Motivation). An example of an item in the scale was "The Chief Flight Instructor clearly defines the steps to reach training program goals".

A beta -testing of the combined items was done using a selected sample of respondents within the collegiate aviation program. The reliability of all the scales were above 0.70 .

\section{Power Analysis and Sample Size Selection}

Several arguments have been proposed regarding the necessary sample size of a covariance structure model (Stevens, 2002). Boomsma and Hoogland (2001) claimed that 200 cases constitute a reliable sample size for a correct model; one in which any problem related to power analysis is less likely to occur. Kline (2005) suggests that sample size estimation should be made based on the number of parameters (20 x number of parameters). Since in this study there were 14 parameters, using the criteria outlined by Kline, an estimated sample size of 280 or more was determined to be adequate to produce a valid model.

\section{Survey Administration}

A confidential Qualtrics ${ }^{\circledR}$ generated online survey instrument was sent to respondent's university issued email address. Faculty members were also requested to post the anonymous link to the survey on their class sites for easy access by their students. The completed responses were stored in a secure online database in accordance with the security protocols required by the university and the Institutional Review Board (IRB). 


\section{Results}

Quantitative survey data was imported from the Qualtrics data collection software into the SPSS software and analyzed. Significant statistical values were set at the 0.05 alpha levels (2-tailed) for most of the analyses unless otherwise specified. The responses from the items in the survey were reduced using factor analysis approach and the resulting items that loaded strongly on factors were tested for content validity and reliability of scale. Descriptive and inferential analyses were conducted using IBM SPSS 23 and IBM AMOS Graphics 23 soft wares. The testing of hypotheses was done using Confirmatory Factor Analysis (CFA) and Structural Equation Models / Path Analysis (SEM-PA).

\section{Demographic Information}

At the end of the response three-week period, two hundred and eighty-two $(n=282)$ responses were completed beyond the consent page and used for analysis. Two hundred and forty-seven- male $(n=247)$ representing $87.6 \%$ and thirty -five female $(n=35)$ representing $12.4 \%$ of the total respondents submitted useable data for analysis. The overall online survey response rate was about $35 \%$ which is adequate for most internal online surveys (Tse-Hua \& Xitao, 2009). Twenty-five responses $(n=25)$ were deleted because the respondents did not go beyond the consent page and that made the data unusable. Details of the demographic data are shown in Table 1.

\section{Question One}

What are the factors that measure the latent construct of SMS initiative? An Exploratory Factor Analysis (EFA) (Principal Axis Factoring) was conducted on the SMS initiative scale using a varimax rotation. An EFA is a statistical method used to find a small set of unobserved variables (also called latent variables, or factors) which may account for the covariance among a larger set of observed variables (Steven, 2002). A factor is an unobservable variable that is assumed to influence observed variables. Items with strong loading on factors were extracted from each set of items in the subscales.

Strongly loaded items on the factors were identified after the rotation and two factors emerged out of SMS Initiative data. The two factors were identified using the factor loadings (loadings higher than 0.5 were used) and the scree plot of the SPSS output. The scree plot helped to visually verify and confirm the number of factors. The two factors that loaded separately were re-designated as SMS policy implementation (SMSPol.Imp) and SMS process engagement (SMSPro.Eng). 
Seventeen items loaded to SMSPol.Imp and five items loaded to SMSPro.Eng. Five items were dropped due to low loadings and most of those items were related to emergency response planning. The cut-off loading thresholds for the identified factors were any value greater than 0.5 and Eigen values greater than 1 was adopted for the Scree plots points of inflexion.

Table 1.

Demographic variables of Gender, Educational Level, and Flight Certificates.

\begin{tabular}{|c|c|c|}
\hline 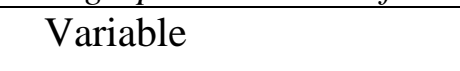 & Value & Percentages $(\%)$ \\
\hline \multicolumn{3}{|l|}{ Gender } \\
\hline Male & 247 & 87.6 \\
\hline Female & 35 & 12.4 \\
\hline Total & 282 & 100.0 \\
\hline \multicolumn{3}{|l|}{ Educational Level } \\
\hline Freshmen & 32 & 11.4 \\
\hline Sophomore & 49 & 17.4 \\
\hline Junior & 56 & 19.8 \\
\hline Senior & 145 & 51.4 \\
\hline Total & 282 & 100.0 \\
\hline \multicolumn{3}{|l|}{ Flight Certificate } \\
\hline Pre-Private & 42 & 13.9 \\
\hline Private & 72 & 25.5 \\
\hline Commercial & 82 & 29.1 \\
\hline Certified Flight Instructor & 86 & 31.5 \\
\hline Total & 282 & 100.0 \\
\hline
\end{tabular}

Note. Percentages are approximate values. 
The two factors SMSPol.Imp and SMSPro.Eng explained about $46 \%$ percent of the variance in the initial Eigen values determined and are shown in Table 3. The SMSPol.Imp denotes the actual implementation practices and strategies by the organizational leadership to ensure the effectiveness of the SMS initiative while the SMSPro.Eng specifies the degree of involvement and acceptance of organizational personnel towards the SMS initiative processes.

Internal consistency and reliability of the scales were determined with the Cronbach's Alpha test in the SPSS 23 software package and pre-determined internal consistency baseline of an alpha $(\alpha)$ of .70 and above was used as a benchmark for high internal consistency as recommended by both Stevens (2002) and Fields (2009). All the items in the various scales showed good reliability above the .70 threshold and the descriptive statistics on the summed items in each scale were conducted. The results were determined to be consistent with the assumptions of normally distributed data. The assumption of normality was confirmed using histograms with a normal distribution curve super-imposed on it and normality plots (P-P plots).

The results indicate that safety compliance had the highest mean scores on a five point Likert-scale $(\mathrm{M}=4.25, \mathrm{SD}=.589)$ and the lowest score was awareness of involvement in a safety-related events $(\mathrm{M}=2.57, \mathrm{SD}=1.007)$. The neutral point was 3 and any value above that was considered desirable. Details of the sample size, mean, standard deviation (SD), instrument reliability and variances explained are shown in Table 2 and Figure 2.

\section{Confirmatory Factor Analysis (CFA)}

A first-order confirmatory factor analysis (CFA) was conducted on all the items describing the constructs SE, SM, SC, SP and TSL. Additionally, the CFA was used to analyse the validity of these scales using a structural equation model path analysis (SEM-PA) techniques. A CFA allows researchers to test hypotheses about a particular factor structure (e.g., factor loading between the first factor and first observed variable is zero). Unlike an EFA, a CFA produces several goodnessof-fit measures to evaluate the model but do not calculate factor scores (Brown, 2006). SPSS AMOS 23 software was used to evaluate the measurement models and determine the factor loadings. Details of the estimates for Maximum Likelihood Estimates (MLE), Standard Error (S.E)., Critical Ratio (C.R)., p-value and Standardized Regression Weights $(\beta)$ are shown in Table 3. 
Table 2.

Summary of Descriptive Statistics, Factor Analysis, Cronbach's Alpha, and Number of Scale Items

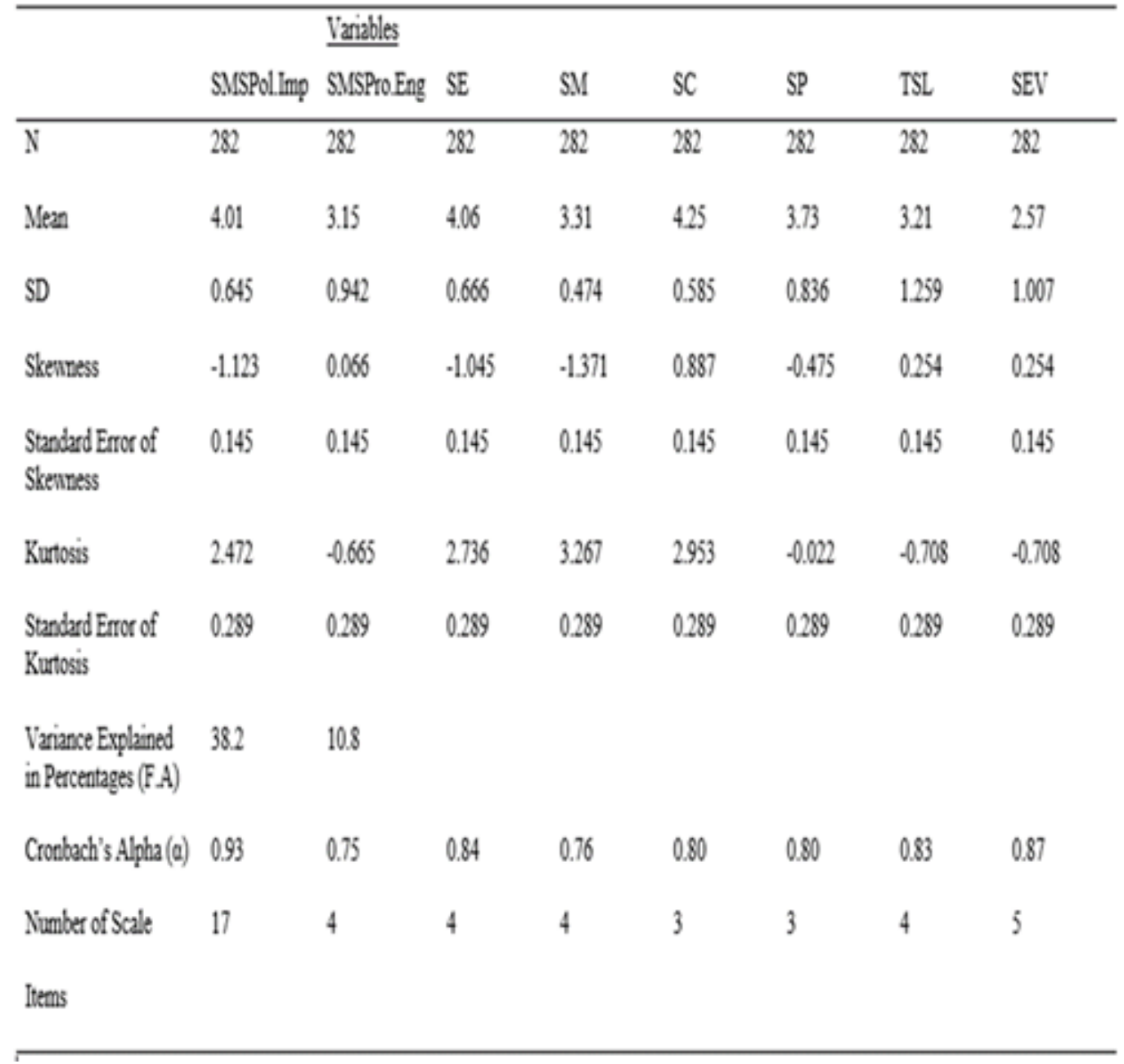




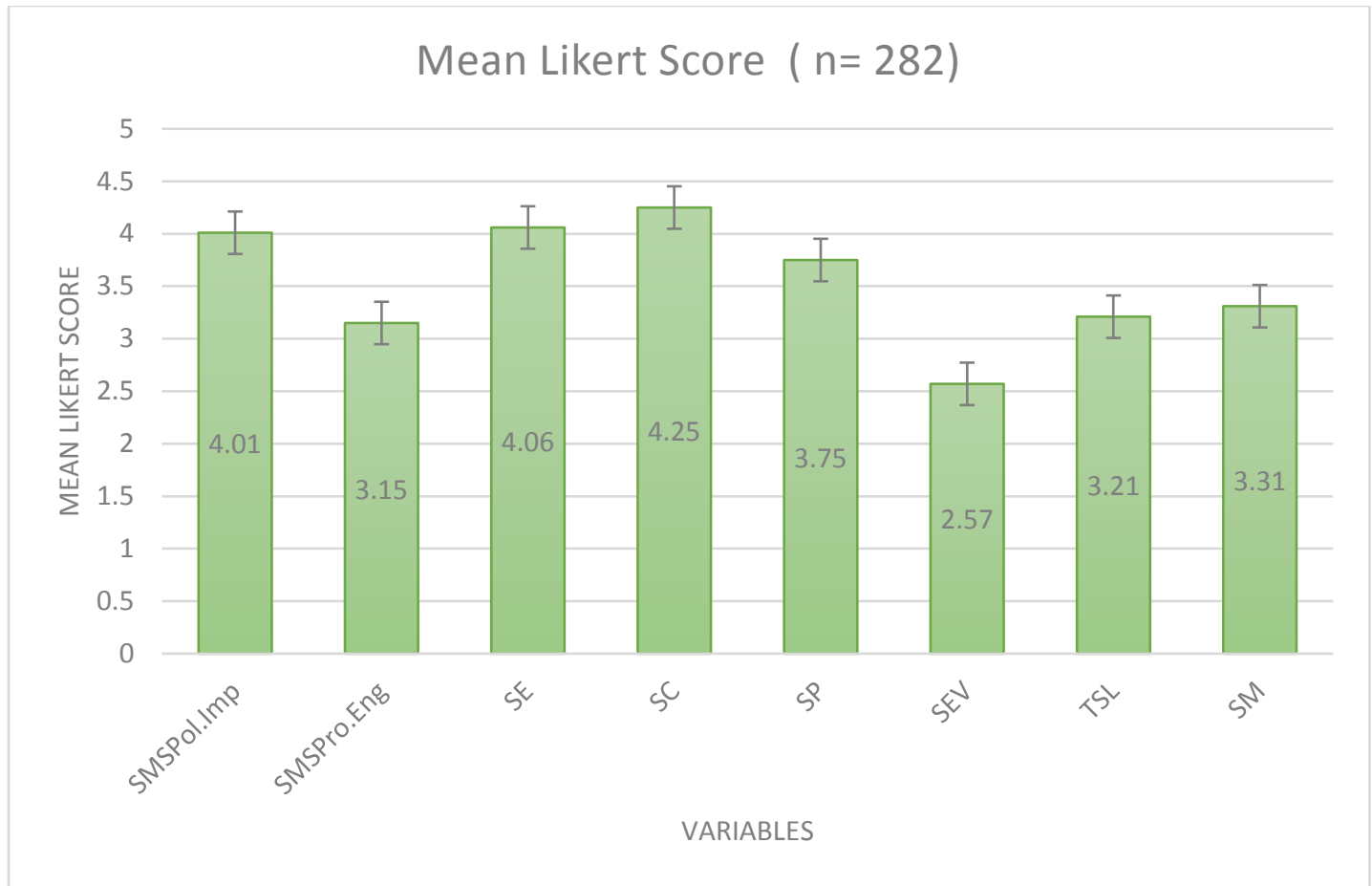

Figure 2. Mean Likert Scores for the Research Variables.

\section{Question Two}

What is the effectiveness of a proposed measurement model as compared to that of a final measurement model that assesses the relationships between SMS initiative, transformational safety leadership, self-efficacy, and the outcome variable safety behavior measured by safety compliance and safety participation, when mediated by safety motivation? To assess the proposed measurement model, the covariance matrix of the variables served as the input to the maximum likelihood estimation procedures of SPSS Amos. A large class of omnibus tests exists for assessing how well a model matches an observed data, and the chi-squared $\left(\chi^{2}\right)$ is a classic goodness-of-fit measure to determine overall model fit. However, the chi-squared is sensitive to sample size, and it becomes difficult to retain the null hypothesis as the number of cases increases (Kline, 2005). Another commonly reported statistic is the Root Mean Square Error of Approximation (RMSEA). A recommended value of 0.05 or less indicates a close fit of the model in relation to the degrees of freedom (Brown, 2006). 
Table 3 .

Maximum Likelihood Estimates of Study Variables using CFA

\begin{tabular}{|c|c|c|c|c|c|c|c|}
\hline & & & Estimate & S.E. & C.R. & $p$ & $\beta$ \\
\hline SE 1 & $<--$ & Self-Efficacy & .720 & .057 & 12.664 & $* * *$ & .67 \\
\hline SE 2 & $<--$ & Self-Efficacy & .667 & .055 & 12.173 & $* * *$ & .85 \\
\hline SE 3 & $<---$ & Self-Efficacy & .641 & .050 & 12.747 & $* * *$ & .83 \\
\hline SM 1 & $<---$ & Safety Motivation & .610 & .045 & 13.484 & $* * *$ & .81 \\
\hline SM 2 & $<--$ & Safety Motivation & .720 & .046 & 15.672 & $* * *$ & .90 \\
\hline SM 3 & $<---$ & Safety Motivation & .647 & .047 & 13.868 & $* * *$ & .83 \\
\hline SC 1 & $<---$ & Safety Compliance & .648 & .045 & 14.388 & $* * *$ & .85 \\
\hline SC 2 & $<--$ & Safety Compliance & .642 & .046 & 13.848 & $* * *$ & .83 \\
\hline SC 3 & $<--$ & Safety Compliance & .654 & .045 & 14.606 & $* * *$ & .86 \\
\hline SP 1 & $<---$ & Safe Part. & .673 & .060 & 11.191 & $* * *$ & .74 \\
\hline SP 3 & $<--$ & Safe Part. & .734 & .074 & 9.918 & $* * *$ & .94 \\
\hline SP 2 & $<---$ & Safe Part. & .922 & .063 & 14.593 & $* * *$ & .66 \\
\hline TSL1 & $<---$ & Trans.SafetyLeader. & .799 & .059 & 13.488 & $* * *$ & .81 \\
\hline TSL4 & $<---$ & Trans.SafetyLeader. & .770 & .052 & 14.828 & $* * *$ & .80 \\
\hline TSL3 & $<---$ & Trans.SafetyLeader. & .782 & .059 & 13.190 & $* * *$ & .86 \\
\hline TSL5 & $<---$ & Trans.SafetyLeader. & .751 & .056 & 13.381 & $* * *$ & .80 \\
\hline
\end{tabular}


Another test statistics is the Comparative Fit Index (CFI) that evaluates the fit of a user-specified solution in relation to a more restricted, nested baseline model, in which the covariance among all input indicators are fixed to zero or no relationship among variables is posited (Brown, 2006, p.86). The fit index CFI ranges from 0 , for a poor fit, to 1 for a good fit. Finally, the Tucker-Lewis Index (TLI) is another index for comparative fit that "includes a penalty function for adding freely estimated parameters" (Brown, 2006, p. 85).

Per Brown (2006), TLI may be interpreted in a similar fashion as CFI, but can have a value outside of the range of 0 to 1 . Hu and Bentler (1999) provided rules of thumb for deciding which statistics to report and choosing cut-off values for declaring significance. When RMSEA values are .05 or below, and CFI and TLI are .95 or greater, the model may have a reasonably good fit. Therefore, it is recommended to not only report $\chi^{2}$ but RMSEA and CFI/TLI. The proposed measurement (fully mediated) model for the research and SEM-PA analysis is shown in Figure 3.

After the preliminary analysis was done using AMOS, the fully mediated model failed to produce any good or acceptable fit, as evidenced by the fit indices: $\mathrm{CMIN}=376.458 ; d f=14 ; p=.000 ; \mathrm{TLI}=.137$; CFI $=.425 ; \mathrm{PNFI}=.281$; RMSEA $=.304$. The Modification indices (MI) in AMOS suggested major modifications produce a more adequate fit for the model. The substantial changes that were recommended to ensure an adequate fit were done in incremental steps and are as follows:

a) Direct path between TSL and SMSPol.Imp.

b) Covariant path from SMSPol.Imp and SE.

c) Covariant path from SMSPro.Eng to SMSPol.Imp.

d) Removal of direct path from SMSPol.Imp and SP.

However, when the analysis was re-run the direct path from TSL to SMSPol.Imp was found to produce additional modifications and a non-significant path coefficient. The direct path was then removed and a new analysis was re-run based on the first model and adding of covariant path from SMSPol.Imp and TSL. The resulting model was better than the initial model but did not produce good fit as shown by the fit indices: $\mathrm{CMIN}=62.681 ; p=.000 ; d f=4 ; \mathrm{TLI}=.336 ; \mathrm{CFI}=$ $.873 ; \mathrm{PNFI}=.125 ; \mathrm{RMSEA}=.228$. 


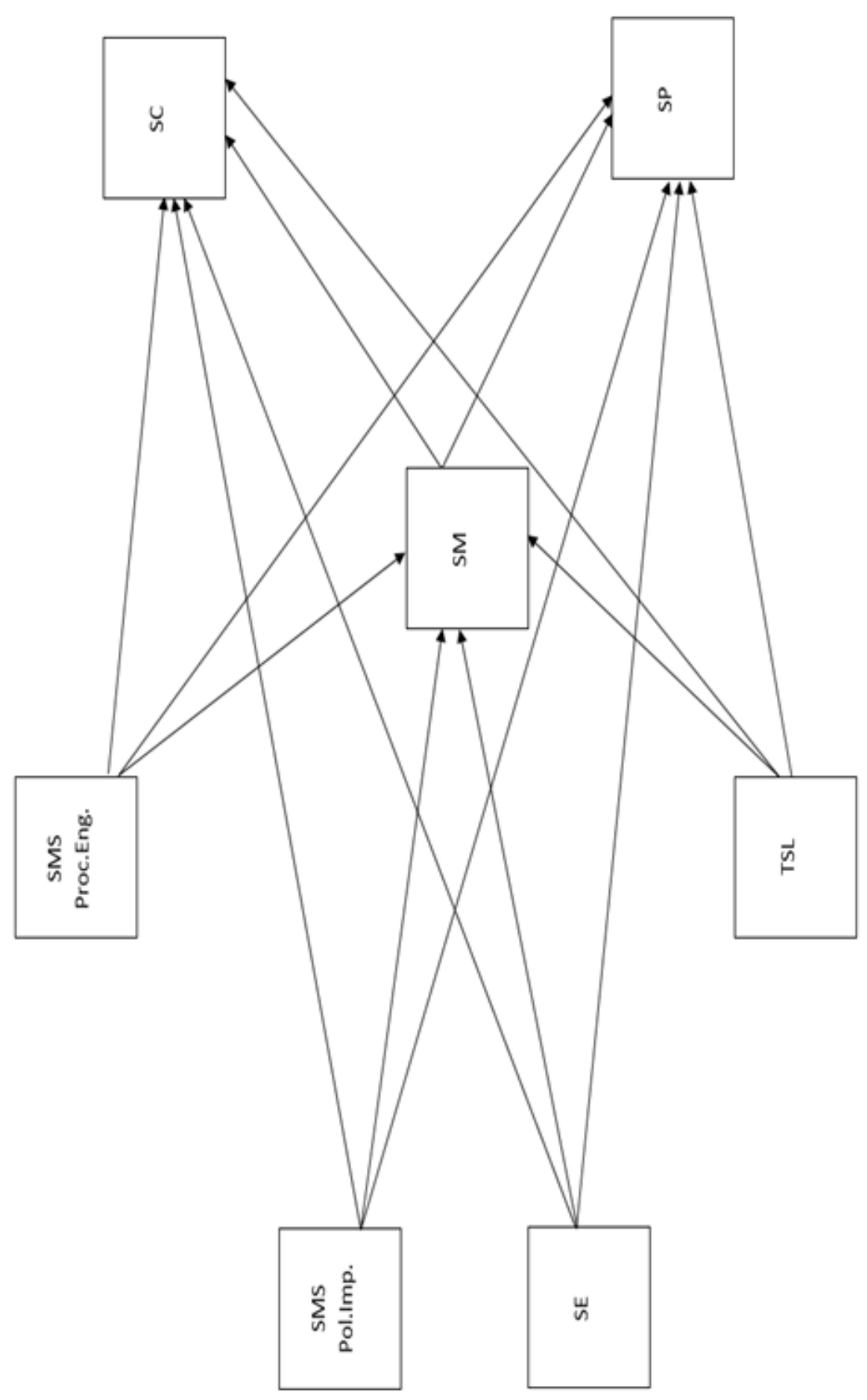

Figure 3. Fully mediated model SMS Proc. Eng. SMS Pol. Imp., TSL, SM, SP, and SC interactions. 
The next set of iteration to the model was done based on the recommendations from the MI and the theoretical consideration of getting a model that will address the research questions. Another covariant path was added between SMSPro.Eng and SE; SC and SP. The MI also recommended the removal of the direct path from TSL to SC to improve the fit. The analysis was re-run and the new fit indices showed good fit: $\mathrm{CMIN}=3.829 ; d f=3 ; p=.280 ; \mathrm{TLI}=.987$; $\mathrm{CFI}=$ $.998 ; \mathrm{PNFI}=.143 ; \mathrm{RMSEA}=.031$.

The measurement model was further improved by a recommendation from the MI for a covariant path between TSL and SMSPro.Eng. The covariant path was added between TSL and SMSPro.Eng and the sum of these modifications yielded the highest incremental improvement to the model fit. The details of the fit index are CMIN $=2.473 ; d f=2 ; p=.290 ;$ TLI $=.999 ;$ CFI $=.989$; PNFI $=.095$; RMSEA $=.029$. Details of the goodness-of-fit for the various iterations in the measurement model is shown in Table 4. The final measurement model with the best fit for the data and the standardized regression weights and significance levels is shown in Figure 4 (covariant paths removed to give clarity). A summary of the maximum likelihood estimate (MLE), standard error (SE), critical ratios (CR), p-values, estimated of effect sizes and hypotheses of the final measurement model with best goodness-of-fit is shown as Table 5.

Table 4.

Goodness-of-fit Estimates for various Measurement Models

Model

$\begin{array}{llllllll}\text { Chi-square } & d f & p & \text { TLI } & \text { CFI } & \text { PNFI } & \text { RMSEA } & \begin{array}{l}\text { LO } \\ \left(X^{2}\right)\end{array}\end{array}$ HI 90

Fully Mediated

Model 1

$\begin{array}{lllllllllll}376.459 & 14 & .000 & .137 & .425 & .281 & .304 & & .277 & .330\end{array}$

Partially Mediated

Model 2

$\begin{array}{llllllllll}62.681 & 4 & .000 & .336 & .876 & .166 & .228 & & .181 & .280\end{array}$

Partially Mediated

Model 3

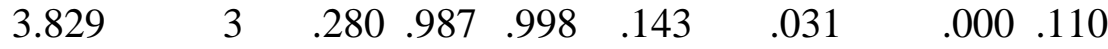

$\begin{array}{lllllllllll}\text { Final Best-fit Model } 4 & 2.473 & 2 & .290 & .999 & .989 & .095 & .029 & .000 & .189\end{array}$ 


\section{Discussion and Conclusion}

The results and findings from the research suggest that in attempting to measure the latent construct of SMS initiative using factor analysis, two underlying factors emerged namely SMS process engagement and SMS policy implementation. The SMS policy implementation $(\alpha=.93)$ explained about $38.2 \%$ of the total variance for the SMS Initiative construct as compared to SMS process engagement $(\alpha=.75)$ which explained about $10.8 \%$ of SMS Initiative construct. It was however very interesting most items on an important component of SMS initiative, Emergency Response Planning (ERP) had poor loadings and had to be dropped. These may indicate that respondents were not familiar with policies and processes related to ERP.

The results obtained corroborates earlier findings by Chen (2014) who also found had two underlying factors measuring SMS among airline pilots in Taiwan. Chen (2014) designated the two underlying scales as SMS policy $(\alpha=.95)$ and SMS practices $(\alpha=.95)$. While Chen (2014) had, the underlying factors explain about $71 \%$ of total variance for the SMS evaluation scale, the present study had about $46 \%$ explanation of total variances in the construct SMS.

A common thread in these studies and the current study reveals that the factor "SMS policy" as a key component and under pins the importance of a coherent SMS policy in any organization that wants to implement an SMS initiative. The findings in this study also highlights SMS policy implementation as essential in explicitly describing core responsibility, authority, lines of accountability and pursuable targets.

SMS implementation in several collegiate aviation programs in the US are in either the "active applicant" or "active participant" level and domain- specific SMS policy guidelines have been relatively new for these collegiate aviation SMS initiatives (FAA, 2015b). Most of the existing guidance materials have been adapted from Part 121 SMS policies for collegiate aviation operations (FAA, 2015a). This finding may help to streamline such adaptation to meet the scope and complexities of flight training and academic environments. 
International Journal of Aviation, Aeronautics, and Aerospace, Vol. 4 [2017], Iss. 2, Art. 4

Table 5.

A summary of the max. likelihood estimate (MLE), standard error (SE), critical ratios (CR), p-values, estimated effect sizes, and hypotheses of final measurement model with best goodness-of-fit

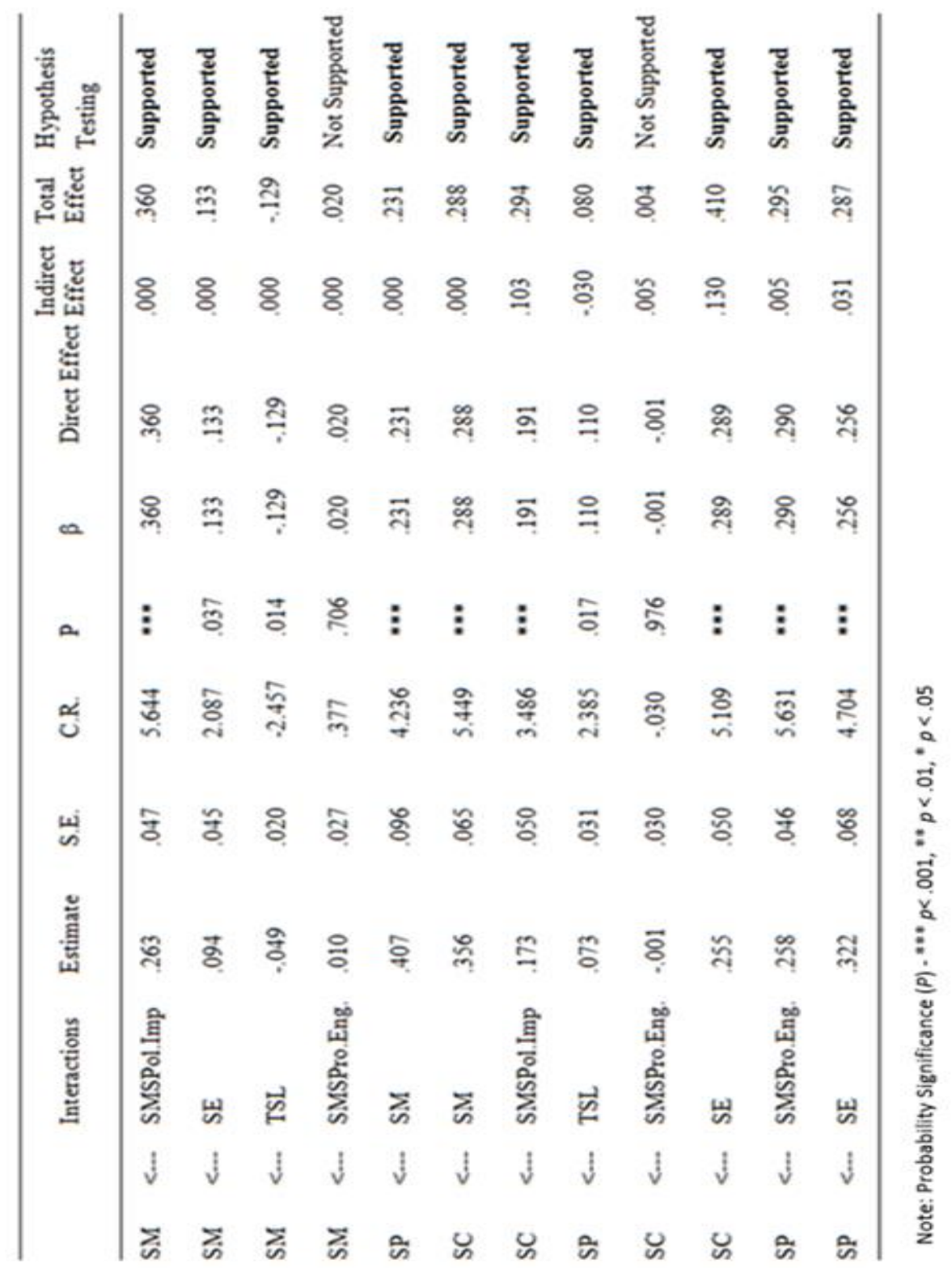




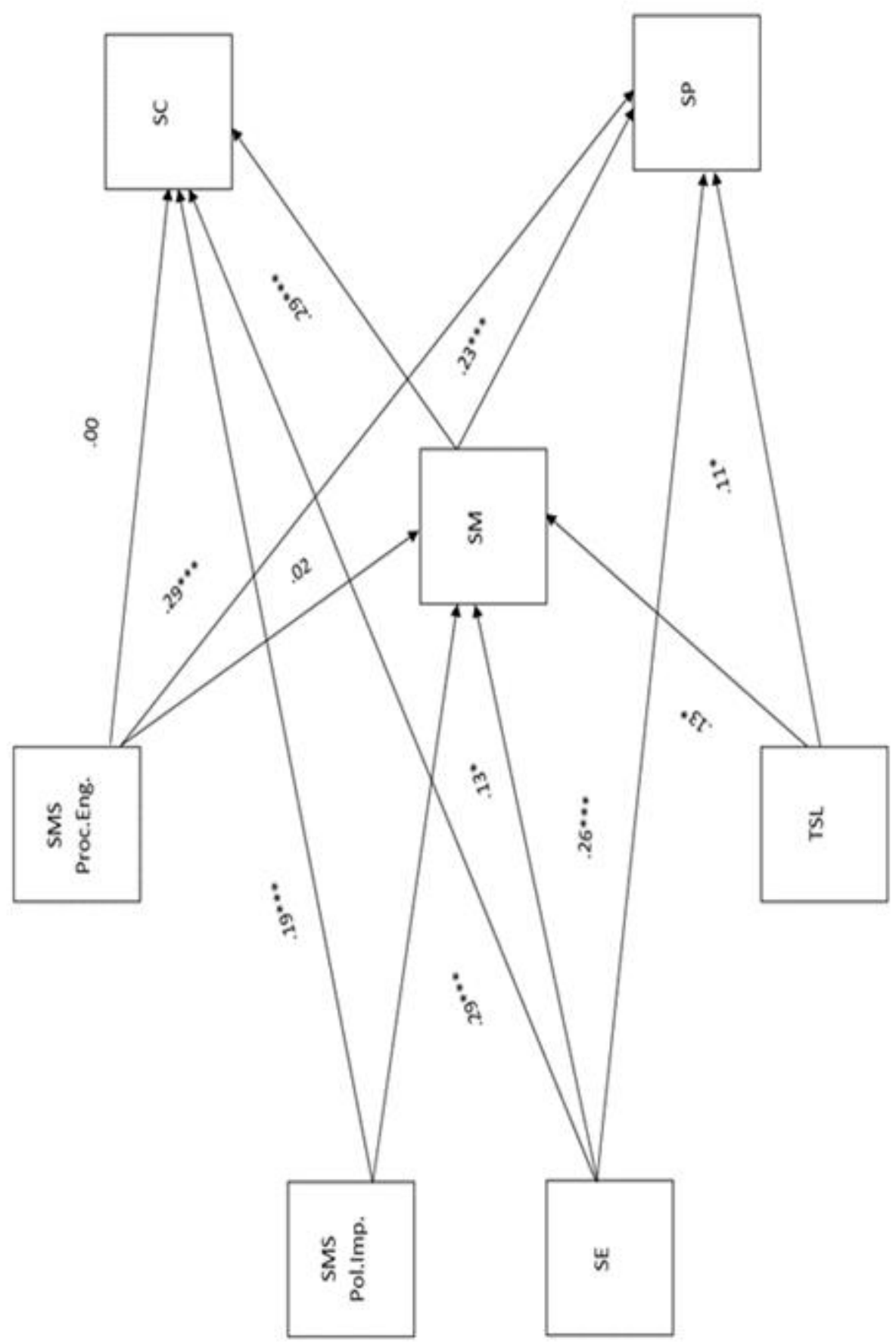

Figure 4. The final measurement model with the best fit for the data, the standardized regression weights, and significance levels. Note: ${ }^{*} p=0.05,{ }^{* *} p=0.01,{ }^{* * *} p=0.001$ 
The results also support extant literature that SMS policy implementation must originate from the highest echelon of authority in an organization and must have ample evidence of top leadership initiatives, commitment and support for the implementation drive (FAA, 2015b). The safety policy implementation must be documented and enshrined in the core mission and vision statement. The safety policy implementation strategies must be visible and communicated wide across the structures of the organization and must be widely known and accepted by all employees as a bona-fide safety policy (IATA, 2012; Wood, 2003).

The findings suggest that sometimes safety policy implementation does not always result in effective SMS process engagement which is the reciprocal gesture or acceptance of the key tenets of the SMS policy by front-line operational personnel such as flight students and flight instructors. The study suggest that top level leadership must use ingenuity and smart promotion strategies to get the necessary "buy-ins" and acceptance from these "sharp-end" operational personnel to get some level of parity between SMS policy implementation and SMS process engagement.

The results suggest that collegiate aviation programs with SMS initiatives must engage individual student, student organizations and flight instructors during the SMS implementation process and in the subsequent continuous improvement processes. The challenges to these recommendations may be the reality of constraints due to time and academic activities for most collegiate aviation students, which may restrict a greater role and engagement in the SMS initiative. Another challenge will be the level of expertise and knowledge that may be required to execute the SMS policy implementation within a collegiate aviation program. However, it may be still beneficial to reach out to these students and flight instructors through SMS initial and recurrent training.

The results indicate that organizational indicators such as perceptions on SMS process engagement have a higher predictive power with regards to respondents' safety participation than SMS policy implementation which did not have any significant direct path to safety participation. The final measurement model showed that the only significant pathway from SMS policy implementation to safety participation was when mediated by safety motivation. The results indicate that although SMS policy implementation may not directly have a positive effect on safety participation, the indirect effect through safety motivation may positively improve safety participation. The results also validate the suggestion by Neal and Griffin (2006) that SMS implementation could be a viable predictor of safety compliance and safety participation. The results further indicate that when 
respondents understand and associate with the SMS policies and how it is implemented, it may motivate them to get involved in safety related activities.

The results from the final measurement model supported the hypothesis that SMS process engagement has a significant positive direct effect on safety participation. The finding is supported by Mc Gregor's Theory $Y$ which has a profound implication for respondents to have "buy-in" and participate in SMS initiated in a collegiate aviation program. Under the conditions outlined by Theory $Y$, this finding may encourage flight students and instructors to seek out responsibility within the SMS process engagement factor and collegiate aviation programs can decentralize the SMS policy implementation and ensure operational level participation under the process owners.

The path way from SMS process engagement to safety motivation was not significant, indicating that safety motivation alone may not influence personnel to actively engage in safety actives if they feel that they are not part of SMS process or have been sidelined in the SMS process implementation. The results therefore implore managers of collegiate aviation programs to actively reach out and engage the students and flight instructors in SMS processes such as safety promotion, safety risk management and very importantly emergency response planning (ERP) which is one area that showed a lot of non-responses from respondents. Flight instructors may be included in safety promotion councils and flight students may be included in flight data monitoring or event review team (ERT) memberships.

The results did not support the hypothesis that there existed a relationship between SMS process engagement and safety compliance. This finding was very interesting and suggests that getting respondents to be part of SMS process may not necessarily affect their safety compliance. A reason for this finding could be the idea that in collegiate aviation program, most of the task and operations are heavily regulated and higher compliance is required by the FAA to maintain certification status. Non-compliance with the requirements of regulations may elicit disciplinary actions and sanctions, hence the need to comply whether one is actively engaged in the SMS initiative processes or not.

The results from the final structural model supported the hypothesis that self-efficacy has a strong direct effect on safety compliance and an even stronger total effect on safety compliance when mediated by safety motivation. This result strongly corroborates findings in earlier research by Schwarzer and Jerusalem (1995) which suggested that respondents with higher perceived self-efficacy are likely to better resist pressure and devote more efforts to improving their workrelated and management performance. 
This finding also supports findings in earlier research (Parasuraman, Molloy, \& Singh, 1993; Prinzel, 2002) that applied self-efficacy as an observed predictor in several studies that investigated pilots' work-related behaviors. The findings also support prior research in the field of teaching and learning in collegiate environment that demonstrated that self-efficacy has effects on the level of motivation, learning and performance and a consistent predictor of behavior and behavioral change (Graham \& Weiner, 1995; Schunk \& Pajares, 2001).

There was a positive direct effect of self-efficacy on safety participation and a positive total effect when mediated by safety motivation. This may be good news for leadership in the collegiate aviation program as it may offset the rather nondirect effect of SMS policy implementation on safety participation in the model. Although self-efficacy may be a function of an individual inherent character it may be improved by formal training which can ensure massive participation from flight students (Chen, 2014; Schunk \& Pajares, 2001). Modules in self-efficacy can be included in flight courses or SMS training programs in collegiate aviation programs.

There was a significant positive relationship between self-efficacy and safety compliance and that is nominally very good, however some researchers have expressed concern that it could be a two-edged sword and that people with high self-efficacy may be extremely goal-oriented at the expense of safety (Prinzel, 2002). Under deadlines, peer pressure, and budget factors, some flight students and instructors with high self-efficacy may decide to logically disregard procedures. This behavior may be termed as the "Superman Syndrome" which creates an aura of invulnerability in the face of obvious risk (Landrum, 2005). That is why the active engagement of students' groups and flight instructors in the SMS initiative could equip them with a sense of process ownership and give them an impetus to peer- review each other in cases of demonstrated undesired safety behavior of colleagues.

The final measurement model indicates that there was a significant direct effect of transformational safety leadership on safety participation and no direct path or effect on safety compliance. There was a positive indirect effect of transformational safety leadership on safety compliance through the mediation of safety motivation. However, even with a small negative direct effect of transformational safety leadership on safety motivation, the total effect on safety participation and safety compliance were significant and positive. 
The results were contrary to earlier findings by Chen (2014) who found out that at the group aspect level ethical or morality leadership did show a significant direct effect on airline pilots' safety compliance. Chen (2014) suggested that pilots by their level of professionalism normally have their behavior dictated by their training and since most airline pilots work as a team with other crew members, sharing information and learning from each other, their safety behaviors may not be influenced by a single fleet manager or chief pilot and recommends that the influence of leadership on pilots' safety compliance may need to be interpreted from a different perspective.

However, the result was similar to empirical findings from extant literature that suggest a positive relationship between transformational leadership and enhanced task performance and safety behavior (Barling, Weber, \& Kelloway, 1996; Fernández-Muñiz, Montes-Peón, \& Vázquez-Ordás, 2014; Howell \& Avolio, 1993; Inness, Turner, Barling, \& Stride, 2010; Pilbeam, Doherty, Davidson, \& Denyer, 2016; Zohar, 2002).

A reason that could be adduced by the counter-intuitive finding of the negative direct relationship between transformational safety leadership and safety motivation may be the idea that when chief flight instructors and other senior flight supervisory staff exhibit high levels of transformational safety leadership traits in a flight program with a "matured" SMS initiative (Active Conformance), flight students and flight instructors become complacent and less motivated to pursue safety objectives because in their opinion the system is inherently safe and dependable with such transformational leadership in place.

That may create a spurious "Dependency Syndrome" that leadership will always ensure a safe operational environment even without the input of these respondents. This trend could potentially be detrimental to continuous improvement and sustenance of the SMS and could lead to operational drift and mitigation decay. Such trends if not checked, can cause an incipient slip of the collegiate safety program into the pre-mitigation period of unsafe attitudes and behaviors.

Another reason that may explain this result is that although top level flight supervisory staff may be exhibiting transformational leadership traits, they may be missing out on some underlying potential motivational factors that can enhance proactive safety behavior in collegiate aviation programs (McLeod, 2014). Two of the four elements of transformational safety leadership are individualized consideration and inspirational motivation and when respondents observe the other components of TSL such as idealized influence and intellectual stimulation but not 
the first two, the net effect may be negative perception of TSL, which could wane safety motivation (Bass \& Riggio, 2006).

Sometimes respondents may not encounter directly, some of these supervisory flight leaders, but will hear negative things about them from third-party sources and that may skew their perceptions about TSL within the organization. On the contrary there may be real issues of poor traits of TSL in these supervisory flight leaders but due to the over-arching proactive safety culture within the organization and the personal expectations and goals of these respondents to place higher value on safety outcomes, they may be self-motivated to ensure safety behavior.

Realistically, these supervisory flight leaders must ensure some level of transactional leadership based on non-individualized hierarchical relationships and specifically Corrective leadership (or active management by exception) that monitors individual performance against standards, detecting errors and correcting them (Zohar, 2002). Therefore, if these supervisory flight leaders exhibit transformational safety leadership traits most of the time, there may be periods where they could become overwhelmed balancing relationship maintenance and attaining operational goals.

This becomes more challenging during times of high-intensity flight training periods and Zohar's Corrective Leadership may create a perception that these supervisory flight leaders do not identify with the cognitive and physiological needs of flight students and instructors such as fatigue and stress. These factors may adversely affect safety motivation. These observations are also theoretically grounded in the Maslow's Hierarchy Theory.

It is therefore imperative that collegiate program managers ensure that flight students and instructors feel emotionally and physically safe and accepted within the flight program to progress and reach their full potential. These flight students and instructors must be shown that they are valued and their opinions respected by their supervisory flight leadership to create an environment that ensures high safety participation and safety compliance as recommended by Maslow.

The result supported the hypothesis that safety motivation has a direct positive effect on both safety participation and safety compliance. This finding supports extant theories that examined the effects of safety motivation on safety behavior such as the Frederick Herzberg's Motivational Theory (Two-Factor Theory) which theoretically explains why safety motivational factors encourage desired and proactive safety behavior in an organization (Greenberg, 2013; Hines, 1973; Neil, 2007). The results also confirm previous findings by Chen (2014) and 
Friewald (2013) that suggested that safety motivation positively influenced airline pilots and flight students respectively to exhibit proactive safety behavior.

The theoretical implications of this finding for a collegiate aviation program with a functional SMS is that policies, processes and procedures may improve the safety motivation of flight students that can positively affect operational practices such as the tendency to act safely, follow training guidelines, and safety instructions. Safety motivation may create an awareness and incentives that operational outcomes are positive as compared to unsafe acts, which may have adverse consequences.

Another implication is that safety motivation may improve safety compliance and is well grounded in the Skinner's Operant Theory. Another theoretical implication of this finding is that when respondents are motivated because of positive reinforcement from safety award programs, they may be more apt to engage in safety compliant behavior and participate in safety activities supported by the Thorndike's Reinforcement Theory.

Based on this finding, it may be beneficial for collegiate aviation programs with SMS to use some form of positive reinforcement such as bonuses for flight instructors who undertake occurrence -free training over a period. Other incentives such as safety awards and public recognition may improve the level of safety motivation. Top -level leadership may also award free training hours to flight students for exemplary safety operations and behavior.

The use of safety motivational strategies such as positive reinforcement could improve flight students and instructors' safety behavior as suggested by the positive direct effect of the causal path in this study. However, top-level leadership should be guided by the limitations of incentives and reinforcement especially in times of high flight training regime in resource constrained environment, where the potential for unsafe working conditions could derail gains made from safety motivations and adversely affects safety behavior (Greenberg, 2013; Reason, 1998).

\section{Limitations}

The conceptual measurement model for this study was subjected to iterative modification to get a good- fit to estimate the strengths of relationships among the constructs, resulting in a final measurement model that aimed at adequately representing the constructs under study. The use of factor analysis (Exploratory and 
Confirmatory) as a data reduction tool resulted in a series of modifications of the final model compared to the proposed model.

The concepts of transformational safety leadership and self-efficacy are highly subjective and were measured as the perceptions of the respondents. Neither the instrument nor the study differentiated among flight level supervisory management relative to the respondents, as they may come into various contacts with diverse people, whose leadership traits at any time may represent operational safety leadership.

\section{Future Direction of Research}

Overall, this study has provided additional insight and literature on SMS to help collegiate aviation management, regulators and policy makers to establish a data- driven approach in formulating policies for SMS implementation and continuous improvement on safety, while reducing safety events and accidents. The study also provides an insightful relationship between the constructs as applicable to a collegiate aviation program that is the active conformance level of an SMS initiative.

Future studies may concentrate on a longitudinal study that will assess how the predictive capabilities of the variables SMS initiative, self -efficacy, safety motivation and transformational safety leadership affects safety behavior over time by sampling a cohort of flight students from the freshman year to the senior year in a collegiate program that transitioning from the active applicant stage of the SMS voluntary program to the final stage of active conformance. 


\section{References}

Adjekum, D. K. (2014a) Safety culture perceptions in a collegiate aviation program: A systematic assessment, Journal of Aviation Technology and Engineering, 3(2). http://dx.doi.org/10.7771/2159-6670.1086

Adjekum, D. K. (2014b). Safety management systems in aviation operations in the United States: Is the return on investment worth the cost? Prime Journal of Business Administration and Management (BAM), 4(4), 14421450. Retrieved from http://www.primejournal.org/BAM/abstracts/2014/apr/Adjekum.htm

Adjekum, D. K., Keller, J., Walala, M., Young, J. P., Christensen, C., DeMik, R. J., Northam, G. (2015). Cross-sectional assessment of safety culture perceptions and safety behavior in collegiate aviation programs in the United States. International Journal of Aviation, Aeronautics, and Aerospace, 2(4). http://dx.doi.org/10.15394/ijaaa.2015.1074

Ajzen, I. (1991). The theory of planned behavior. Organizational Behavior and Human Decision Processes, 50(2), 179-211.

Ajzen, I. (2005). Attitudes, Personality and Behavior. 2nd ed. New York, NY: Open University Press.

Aviation Safety Network (ASN). (2008, October 28). aviation-safety.net. Retrieved from http://aviation-safety.net/wikibase/wiki.php?id=43643

Barling, A. J., Weber, T., \& Kelloway, E. K. (1996). Effects of transformational leadership training on attitudinal and financial outcomes: A field experiment. Journal of Applied Psychology, 81, 827-832.

Barling, A. J., Loughlin, C., \& Kelloway, E. K. (2002). Development and test of a model linking safety-specific transformational leadership and occupational safety. Journal of Applied Psychology, 87(3), 488-496.

doi: 10.1037//0021-9010.87.3.488.

Bass, B. M., \& Riggio, R. E. (2006). Transformational Leadership. 2nd ed. New York : Psychology Press/Routledge. 
Boomsma, A., \& Hoogland, J. J. (2001). Structural equation modeling: Present and future: A Festschrift in honor of Karl Jöreskog. Chicago, IL: Scientific Software International.

Brown, T.A. (2006). Confirmatory Factor Analysis for applied research. New York, NY: Guilford Press.

Chen, C.F., \& Chen, S.C. (2012). Scale development of Safety Management System evaluation for the airline industry. Accident Analysis and Prevention 47, 177-181. doi: 10.1016/j.aap.2012.01.012

Chen, C.-F.-C. (2014). Measuring the effects of Safety Management System practices,morality leadership and self-efficacy on pilots' safety behaviors: Safety motivation as a mediator. Safety Science, 62(14), 376-385. http://dx.doi.org/10.1016/j.ssci.2013.09.013

Cohen, A. (1977). Factors in successful occupational safety programs. Journal of Safety Research, 9, 168-178.

Conchie, S. M., \& Donald, I. J. (2009). The moderating role of safety-specific trust on the relation between safetyspecific leadership and safety citizenship behaviors. Journal of Occupational Health Psychology, 14, 137-147.

Cooper, M. D. (2000). Towards a model of safety culture. Safety Science, 36(2), 111-136. http://dx.doi.org/10.1016/S0925-7535(00)00035-7

Dekker, S.W. ( 2011). The criminalization of human error in aviation and healthcare: a review. Safety Science. 49(2), 121-127.

Dillman, B., Voges, J., \& Robertson, M. (2010). Safety occurrences: Student perceptions regarding failure to report. Journal of Aviation Management and Education, 1. Retrieved from http://www.aabri.com/manuscripts/09261.pdf

Edwards, J. R., Knight, D. K., Broome, K, M., \& Flynn, P. M. (2010). The Development and validation of a Transformational Leadership Survey (TLS) for substance use treatment program. Substance Use Misuse, 45(9), 1279-1302. doi: 10.3109/10826081003682834. 
Federal Aviation Administration. (2012). Safety Management System (SMS) for pilot schools and training centers. Washington, D.C.: Air Traffic Organization NextGen \& Operations Planning, Office of Research and Technology Development.

Federal Aviation Administration. (2013). Safety Management System: SMS Pilot Projects Overview. Washington, D.C. Retrieved from http://www.faa.gov/about/initiatives/sms/pilot_projects/overview/

Federal Aviation Administration. (2015, January 8). Safety Management System for aviation service providers: AC 120-92B [PDF]. Washington D.C.: Federal Aviation Administration. Retrieved from http://www.faa.gov/documentLibrary/media/Advisory_Circular/AC_12092B.pdf

Federal Aviation Administration. (2015, March 9). Safety Management System Voluntary Program Guide (AFS-900-002-G201) [PDF]. Washington D.C.: Federal Aviation Administration.

Fernández-Muñiz, B., Montes-Peón, J. M., Vázquez-Ordás, C. J. (2007). Safety management system: Development and validation of a multidimensional scale. Journal of Loss Prevention in the Process Industries, 20(1), 5268. doi:10.1016/j.jlp.2006.10.002

Fernández-Muñiz, B., Montes-Peón, J. M., Vázquez-Ordás, C. J. (2014). Safety leadership, risk management and safety performance in Spanish Firms. Safety Science (70). 295-307. http://dx.doi.org/10.1016/j.ssci.2014.07.010

Field, A. (2009). Discovering statistics using SPSS (3rd ed.). London, UK: Sage Publications, Ltd.

Freiwald, D, R. (2013) The effects of ethical leadership and organizational safety culture on safety outcomes . Dissertations and Theses. Paper 55. Retieved from http://commons.erau.edu/edt

Freiwald, D., Lenz-Anderson, C., \& Baker, E. (2013). Assessing safety culture within a flight training organization. Journal of Aviation/Aerospace Education and Research, 22(2). Retrieved from http://commons.erau.edu/db-applied-aviation/2 
Fogarty, G. J., \& Shaw, A. (2009). Safety climate and the theory of planned behavior: Towards the prediction of unsafe behavior. Accident Analysis and Prevention. doi: 10.1016/j.aap.2009.08.008

Gill, G.K., \& Shergill, G. S. (2004). Perceptions of safety management and safety culture in aviation industry in New Zealand. Journal of Air Transport Management, 10(2004), 233-239. DOI : 10.1016/j.jairtraman.2004.02.002

Graham, S., Weiner, B. (1995). Theories and principles of motivation. In: Berliner,D.C., Calfe, R.C. (Eds.), Handbook of educational psychology. New York, NY: Simon \& Schuster Macmillan.

Greenberg, J. (2013). Managing behavior in organizations (6 ${ }^{\text {th }}$ ed.). Upper Saddle River, New Jersey: Pearson Education.

Hines, G. H. (1973). Cross-cultural differences in two-factor motivation theory. Journal of Applied Psychology, 58(3): 375-377. doi:10.1037/h0036299

Howell, J. M., \& Avolio, B. J. (1993). Transformational leadership, transactional leadership, locus of control and support for innovation: Key predictors of consolidated-business-unit performance. Journal of Applied Psychology, 78(6), 891-902.

Hsu, Y.L., Li, W.C., Chen, K.W. ( 2010). Structuring critical success factors of airline safety management system using a hybrid model. Transportation Research Part E 46, 222-235.

Hu, L. T., \& Bentler, P. M. (1999). Cutoff Criteria for fit indices in covariance structure analysis: conventional criteria versus new alternatives. Structural Equation Modeling, 6, 1-55. doi:10.1080/10705519909540118

Inness, M., Turner, N., Barling, J., Stride, C.B. (2010). Transformational leadership and employee safety performance: a within-person, between jobs design. Journal of Occupational Health Psychology. 15(3), 279-290. http://dx.doi.org/10.1037/a0019380

International Air Transport Association. (2012). International Operational Safety Audit Guidelines . Retrieved from http://www.iata.org/ps/certification/iosa/Pages/index.aspx 
International Civil Aviation Organization. (2009). Safety Management Manual (SMM) (Doc.9859 [2nd ed.]). Montreal, Canada: Author.

International Civil Aviation Organization (2013). Safety Management Manual, Doc 9859 AN/474 ( $3^{\text {rd }}$ ed.). Montreal, Canada: Author.

Kapp, E.A. (2012). The influence of supervisor leadership practices and perceived group safety climate on employee safety performance. Safety Science. 50, 1119-1124.

Kelloway, E. K., Mullen, J., \& Francis, L. (2006). Divergent effects of transformational and passive leadership on employee safety. Journal of Occupational Health Psychology,11, 76-86. http://dx.doi.org/10.1037/1076-8998.11.1.76

Kline, R. B. (2005). Principles and practice of structural equation modeling. New York, NY: The Guilford Press.

Landrum, G. N. (2005). "The Superman Syndrome"- The magic of myth in the pursuit of power. Lincoln, NE: iUniverse,Inc.

Liou, J.H., Chuang, M.L. (2010). Evaluating corporate image and reputation using fuzzy MCDM approach in airline market. Quality \& Quantity 44(6), 1079-1091.

Maslow, A. H. (1970). Motivation and personality. New York, NY: Harper \& Row.

McLeod, S. A. (2014). Maslow's hierarchy of needs. Retrieved from www.simplypsychology.org/maslow.html

National Transportation Safety Board (2010, November 17). NTSB Aviation query brief website. Retrieved from http://www.ntsb.gov/aviationquery/brief2.aspx?ev_id=20101117X70315 ntsbno=WPR11FA050\&akey $=1$

Neal, A., \& Griffin, M. A. (2002). Safety climate and safety behaviour. Australian Journal of Management, 27(1), 67-78. doi: 10.1177/031289620202701S08 
Neal, A., \& Griffin, M. A. (2006). A study of the lagged relationships among safety climate, safety motivation, safety behavior, and accidents at the individual and group levels. Journal of Applied Psychology, 9(4), 946 -953. doi: 10.1037/0021-9010.91.4.946

Neal, A., Griffin, M. A., \& Hart, P. M. (2000). The impact of organizational climate and individual behavior. Safety Science, 34(3), 99-109. doi: 10.1177/031289620202701S08

Neil, C. (2007). Psychology: The science of behavior. Upper Saddle River, NJ: Pearson Education, Inc.

Nunally, J. (1978). Psychometric Theory (2 nd ed). New York, NY: McGraw-Hill.

Parasuraman, R., Molloy, R., Singh, I.L.(1993). Performance consequences of automation-induced "complacency." International Journal of Aviation Psychology 3(1), 1-23.

Pilbeam, C., Doherty, N., Davidson, R., Denyer, D. (2016). Safety leadership practices for organizational safety compliance: Developing a research agenda from a review of the literature. Safety Science, 86. 110-121. doi:10.1016/j.ssci.2016.02.015

Prinzel, L.J. (2002). The relationship of self-efficacy and complacency in pilot automation, Interaction. NASA/TM-2002-211925.

Reason, J. T. (1997). Managing the risks of organizational accidents. Burlington, VT: Ashgate,

Reason, J. T. (2008). The human contribution: unsafe acts, accidents and heroic recoveries. Burlington, VT: Ashgate.

Remawi, H., Bates, P., Dix, I. (2011). The relationship between the implementation of a safety management system and the attitudes of employees towards unsafe acts in aviation. Safety Science 49, 625-632.

Schultz, D. P., Schultz, S. E. (2010). Psychology and Work Today: An Introduction to Industrial and Organizational Psychology $\left(10^{\text {th }}\right.$ ed.). New York, NY: Prentice Hall. 
Schwarzer, R., \& Jerusalem, M. (1995). Generalized Self-Efficacy scale. In J. Weinman, S. Wright, \& M. Johnston (Eds.) Measures in health psychology: A user's portfolio. Causal and control beliefs. 35-37. Windsor, UK: NFER-NELSON.

Schunk, D.H., Pajares, F. (2001). The development of academic self-efficacy. In: Wigfield, A., Eccles, J. (Eds.), Development of achievement motivation. San Diego, CA: American Press.

Skinner, B. (1953). Science and Human Behavior. New York, NY: MacMillan Stevens, J. (2002). Applied multivariate statistics for the social sciences $\left(4^{\text {th }} \mathrm{ed}\right.$.). Hillsdale, NJ: Erlbaum.

Sorenson, P. (2015). "Theory X and Theory Y". Management. doi:10.1093/obo/9780199846740-0078

Stewart, M. (2010). Theories X and Y, Revisited. Oxford Leadership Journal, 1 (3). 1-5. http://www.oxfordleadership.com/journal/vol1_issue3/stewart.pdf

Stolzer, A. J., Halford, C.D., Goglia, J.J. (2008). Safety Management System in aviation. Burlington, VT: Ashgate Publishing.

Stolzer, A.J., Halford, C.D., Goglia, J.J. (2011). Implementing Safety Management Systems in aviation. Surrey, UK: Ashgate Publishing.

Transport Canada. (2005). Safety Management System: An assessment guide TP 14326E. Ottawa, Canada: Civil Aviation Communications Centre.

Tse-Hua, S., Xitao Fan. (2009) Comparing response rates in e-mail and paper surveys: A meta-analysis, Educational Research Review, 4(1), 26-40. http://dx.doi.org/10.1016/j.edurev.2008.01.003

University of North Dakota Aviation. (2012). UND Aviation Safety Managements System implementation phases $1 \& 2$ report. Grand Forks, ND: Gary Ullrich.

Vinodkumara, M.N., \& Bhasib, M. (2010). Safety management practices and safety behaviour: Assessing the mediating role of safety knowledge and motivation. Accident Analysis and Prevention, 42, 2082-2093. 
von Thaden, T. (2008). Safety culture in commercial aviation operations: Technical report HFD-08-3/FAA-08-1. Savoy, IL: University of Illinois Human Factors Division. Retrieved from http://www.aviation.illinois.edu/avimain/papers/research/pub_pdfs/techre ports/08-03.pdf

Wallace, C., Chen, G. (2006). A multilevel integration of personality, climate, self-regulation, and performance. Personnel Psychology, 59, 529-557. doi: $10.1111 /$ j.1744-6570.2006. 00046.x

Zohar, D. (1980). Safety climate in industrial organizations: Theoretical and applied implications. Journal of Applied Psychology, 65, 96-102. doi: 10.1037/0021-9010.65.1.96

Zohar, D. (2002). The effects of leadership dimensions, safety climate, and assigned priorities on minor injuries in work groups. Journal of Organizational Behavior, 23,75-92. doi:10.1002/job.130

Zohar, D., \& Luria, G. (2004). Climate as a social-cognitive construction of supervisory safety practices: Scripts as proxy of behavior patterns. Journal of Applied Psychology, 89(2), 322-333. doi: 10.1037/0021-9010.89.2.322 